\title{
Occupational Rehabilitation Policy and Practice in the Philippines: Initiatives and Challenges
}

\author{
Maria Elizabeth Olavides-Soriano • \\ Enrique Ampo $\cdot$ Reuben Escorpizo
}

Published online: 29 January 2011

(C) Springer Science+Business Media, LLC 2011

\begin{abstract}
Introduction Challenges to occupational rehabilitation or work integration or reintegration which include the socio-political system, poor labour infrastructure, legislation implementation and monitoring limit work participation of an estimated eight million Filipinos with disabilities. This paper aims to present government-level initiatives and ongoing challenges of occupational rehabilitation as a field of practice and research in the Philippines. Methods We performed a review of occupational rehabilitation literature relevant to the Philippines looking at legislation, policies, and practice. Results While several socio-political mechanisms exists, we found no concrete
\end{abstract}

M. E. Olavides-Soriano

Public Administration Program, Graduate School Xavier

University-Ateneo de Cagayan, Cagayan de Oro, Philippines

M. E. Olavides-Soriano

History, International Studies and Political Science Department,

Xavier University - Ateneo de Cagayan, Cagayan de Oro,

Philippines

E. Ampo

Federation of Persons with Disabilities Association, Cagayan de Oro, Philippines

R. Escorpizo ( $\square)$

Swiss Paraplegic Research (SPF), Guido A. Zäch Str. 4,

6207 Nottwil, Switzerland

e-mail: reuben.escorpizo@paranet.ch

R. Escorpizo

ICF Research Branch of WHO Collaborating Centre for the Family of International Classifications in German,

Nottwil, Switzerland

R. Escorpizo

Department of Health Sciences and Health Policy, University

of Lucerne, and at SPF, Nottwil, Switzerland information on the surveillance or distinction of services and their effectiveness provided under occupational rehabilitation and there was also no systemic reporting of the characteristics of the population (persons with disabilities vs. injured workers) requiring those services-despite the effort of the Philippines in adopting a state policy for the total development of persons with disabilities towards gainful employment. Conclusions The dearth of information and literature in occupational rehabilitation is likely related to the scarcity of research in the broader area of occupational safety and health and work disability management in the Philippines. The findings of this study could guide work disability management and address further development of infrastructure in occupational rehabilitation in the Philippines.

Keywords Occupational rehabilitation - Vocational rehabilitation · Work - Employment

\section{Introduction}

Health conditions or health-related events could negatively impact an individual's participation with his or her occupation which might result in either absence from work or limitations and restrictions at work. As it is, occupation is a major life area to most people which makes it imperative to address the issue. The process of returning the worker back to work or engaging the individual with a new job then becomes essential. This process has been referred to, in a broad sense, as occupational rehabilitation, or work rehabilitation, or vocational rehabilitation [1]. The term occupational rehabilitation, however, will be used in this article.

Occupational rehabilitation is a multidisciplinary approach with the aim of returning a worker towards 
gainful employment or facilitating participation in the workforce. It is a complex process which consists of multiple players and an array of interactions of several factors that may impact the functioning of the worker [1]. These factors may include those that relate to the individual worker, the work, the workplace, and beyond the traditional confines of "work" (even to include the value of societal and household role and overall quality of life) [2-4].

\section{Occupational Rehabilitation in the Philippines}

Legislation and Gap in Implementation

In the Philippines, occupational rehabilitation, commonly referred to as vocational rehabilitation, is used under the auspices of the National Occupational Safety and Health (NOSH) of the Department of Labor and Employment (DOLE) and the National Council for the Welfare of Disabled Persons (NCWDP). By legislation, Article 13, Section 13 of the Philippines Constitution (1987) states that the "State shall establish a special agency for disabled persons for rehabilitation, self-development and self-reliance, and their integration into the mainstream of society". This legislation mandates the NCWDP to facilitate occupational rehabilitation and the integration or reintegration of people with disabilities (PWDs). A comprehensive disability law is contained in the passage of the Magna Carta for Disabled Persons (Republic Act or RA 7277) in 1995 which provides three primary focus areas-education, employment and occupational rehabilitation [5]. The implementing rules and regulations of RA 7277 define occupational rehabilitation as integrated measures that shall serve to develop the skills and potentials of PWDs and enable them to engage or reengage in livelihood or income generating activities and compete or re-compete favorably for available productive and remunerative employment opportunities in the labor market [6].

A National Plan of Action for the Decade of Persons with Disabilities was also enacted for 2003 until 2012. Efforts at promoting an inclusive society include an employment quota scheme for PWDs with 5\% of all casual, emergency and contractual positions in the Department of Social Welfare and Development (DSWD), Department of Health (DOH), Department of Education (DOE) and other government agencies offices, or corporations engaged in social development [7]. However, these legislative and policy initiatives do not address mechanisms for the implementation and monitoring of occupational rehabilitation programs as a function of the integration or re-integration of PWDs in the labor market.
Policy and Regulations Governing Workers' Compensation

The government of the Philippines provides an Employees Compensation Program (ECP) which includes a package of benefits for employees in the public and private sector and their dependents in the event of work-related contingencies such as sickness, injury, disability, or death [8]. The Employees' Compensation Commission (ECC), a quasijudicial corporation attached to DOLE, was created to implement the ECP. The ECC is mandated by law to provide appropriate compensation to workers, and formulates policies and guidelines for the improvement or increase in benefits under the employees' compensation program. The ECC also reviews and decides on appeal of employment compensation claims and initiates policies and programs toward adequate occupational health and safety and accident prevention in the work environment, in the area of rehabilitation and other related programs and activities, and funding. The ECC was created in November 1, 1974 by virtue of Presidential Decree 442 or the Labor Code of the Philippines and became fully operational with the issuance of Presidential Decree 626 on January 1, 1975 [8].

To advocate for the welfare of the workers, the ECC envisions its role in social security promotion that manages a sound, strong, and wisely invested state insurance fund and delivers prompt, effective, and efficient package of services and benefits for the workers. At present, the commission has identified programs and activities under four key results areas which include work contingency prevention services to workers, curative services and compensatory benefits to workers, rehabilitative services, and support services [8]. Work contingency prevention services include dialogue with the employers and unions, workplace assessments, medical examinations, incidence monitoring, and public information and assistance in processing claims. Curative services and compensatory benefits can refer to procedural review of benefits granted, resolution of claims that were filed, case monitoring, providing recurrent medical services (e.g. dialysis treatment), and counseling and medical services. Under rehabilitative services, programs and activities can include counseling, retraining or training with a new job, job placement, and financial assistance. Finally, support services mainly include those that are relevant to the government system (agency) and infrastructure where workers file claim and seek care. These services are accreditation of hospitals and physicians, review and update of Employment Compensation (EC) policies, continuous service improvement and quality management, information technology support, database maintenance, and ensuring the viability of the fund that finances benefits. Other services under support 
services include financial support for the operation of EC processing, physical infrastructure support such as offices, and EC personnel management [8]. These programs are indicative of the breadth of benefits, in principle, that workers with injury or disability in the Philippines are entitled to, but unfortunately do not specifically operationalize the services focused on the worker with injury (e.g. referral to health services such as physical therapy after an event).

There is a need to assess the ECP because of the fragmented process of implementation under three government agencies namely (1) the ECC for policy formulation and appealed cases disposition, (2) the Social Security System (SSS) (employees from private companies) and the Government Service Insurance System (GSIS) (public employees) for service delivery, and (3) the State Insurance Fund (SIF) for administration. The present ECP is focused on benefits payment and has neglected work contingency prevention and the rehabilitation of workers with work disability. Two legislative bills to facilitate the workers' compensation program have been filed in the Congress of the Philippines in 2004 but have not been passed into law yet.

\section{Scan of the Labor Force Trend and Makeup}

In the Philippines, the labor force expanded by $4.6 \%$ from about 37 million in January 2009 to about 39 million the following year. Likewise, the labor force participation rate increased by $1.2 \%$ (from its previous rate of $63.3 \%$ ). Employed individuals reached around 36 million in January 2010, rising by about 5\% compared to a year ago. Employment in industry and service sectors increased by $9.6 \%$ and $7.5 \%$, respectively. Bulk of the increase in employment in these two sectors was attributed to construction and wholesale and retail trade. In contrast, employment in agricultural sector went down by $0.4 \%$ [9]. Several studies confirm that occupational safety and health (OSH)-relevant conditions in micro- firms and the informal sector (informal as such in the Philippines) to include metal and wood working, garment and footwear, small-scale mining and Pa-aling fishing continue to be saddled with a host of risks and hazards- which range from exposure to chemicals and sub-standard equipment and tools to unhygienic working environment [10]. Pa-aling is an alternative method used by large-scale fishing companies. Instead of using stones to drive fishes out of corral beds, the swimmers use tubes that release high-pressure air. This method is effective in driving fishes out of their habitat.

In a survey conducted by the Philippine Bureau of Labor and Employment Statistics (BLES) in 2008 in coordination with the country's regional offices of the Department of Labor and Employment (DOLE) which covered 6,460 non-agricultural sample establishments employing 20 or more workers nationwide, about $84 \%$ of these establishments were engaged in wholesale and retail trade; repair of motor vehicles, motorcycles, personal and household goods industry.

Community, social and personal services industry may be considered as the most diverse among all industries in the Philippines, and covered the second smallest employment next to mining and quarrying. It accounted for about 70,000 workers or a meager $2.3 \%$ of the total 3 million employed in establishments with 20 or more workers. More than one-third $(35.4 \%)$ of workers in this sector are females while close to $8 \%$ are young workers. Moreover, the community, social and personal services industry is mainly composed of establishments engaged in sewage and refuse disposal, sanitation and similar services; activities of membership organizations; recreational, cultural and sporting activities; and other service activities including washing and dry cleaning of clothes, hairdressing and beauty treatment; funeral and other related services; and other personal activities such as social escort service activities, sauna and steam bath, and slendering and body building activities [11].

\section{Lack of Infrastructure and Data System}

There is no official and leading data to report "events" of interest to occupational rehabilitation in the Philippines, we are left to provide our insights with what limited information is available. For example, with an employment of about 0.4 million workers composed predominantly of young and female workers in the wholesale and retail trade industry, it is important to characterize those "events" that require examination and the consequent prevention and rehabilitation of people with work-related accidents and illnesses. Only 3 out of every 10 establishments in wholesale and retail trade industry maintained Employees' Work Accident/Illness Report and Annual Medical Report. A smaller proportion of the establishments kept records of Annual Work Accident/Illness Exposure Data (14.3\%) and Minutes of Meeting of Health and Safety Committee (12.9\%). About two-fifths of the establishments in other community, social and personal services kept records of Employees Work Accident/Illness Report while only 1 out of every 3 establishments maintained Annual Medical Report. Less than 15\% had Annual Work Accident/Illness Exposure Data and Minutes of Meeting of Health and Safety Committee.

Only few establishments in the wholesale and retail trade industry had certifications from the International Organization for Standardization (ISO). Only one out of every 20 establishments had been certified on ISO 9001:2000_ Quality Management System. Few establishments held 
certifications on OHSAS 18001-Occupational Health and Safety Management Standard (2.4\%) and ISO 14001Environmental Management Standard (1.8\%). Noticeably, few establishments in other community, social and personal services had certification from the ISO. Of the certified establishments, only $5.9 \%$ were certified on Occupational Health and Safety Management Standard (OHSAS 18001), while $3.5 \%$ were certified on Environmental Management Standard (ISO 14001). Other establishments have certifications on SA 8000-Social Accountability Standard $(2.8 \%)$ and ISO 9001:2000-Quality Management System $(1.3 \%)$ [12]. It is clear from these findings that there is a poor state of documenting (to begin with) occupational health and safety issues. Hence, the lack of labor standard could not lead to a sound basis for occupational rehabilitation.

The rationale, however, for pursuing the occupational rehabilitation agenda in the Philippines is evident. In 2007, the rates of cases of occupational injuries with workdays lost in non-agricultural establishments were high in manufacturing and bus line operations, albeit causing non-fatal incapacity [13]. In the same report, common causes of occupational injuries cover superficial injuries and open wounds; fractures, dislocations, sprains and strains; traumatic amputations; concussion and internal injuries; burns, corrosions, scalds and frostbites; acute poisoning and infections; and foreign body in the eye. Of the 20,386 recorded occupational injuries, superficial injuries and open wounds; dislocations, sprains and strain; and burns, corrosions, scalds and frostbites topped the list [13]. However, all the above findings only provide the bare minimum data because many injuries and illnesses are not reported and more critically, comprehensive work data relating to post-injury period are lacking. Moreover, longitudinal comparison has so far been inconclusive because of the lack of reporting criteria, if ever available [14]. With rapidly changing technologies and work organizations, the international movement of labor, the rise in female employment and the "flexibilization" of work, the challenge of addressing occupational rehabilitation in the Philippines becomes even more difficult.

The lack of a robust infrastructure and a uniform data system can be tied to the lack of clear model (conceptual or practical) on occupational rehabilitation in the Philippines. Models or frameworks can play a vital role in capturing injury and occupational rehabilitation statistics. An example of a model is the International Classification of Functioning, Disability and Health (ICF) [15] by the World Health Organization from a generic perspective. The ICF has been recently used to provide relevant domains ( "what to measure") of functioning and disability in occupational rehabilitation [1]. Another potential model integrates the ICF in assessing work functioning in relation to the fit between the worker and the environment over time [16], which is important in complex claims that go in and out of the workers' compensation system because of a chronic health condition. Models, if utilized by the DOLE for example, can provide guidance on what services are needed and how effective the services are.

\section{From International to Local Policymaking}

The International Labour Organization (ILO) is the lead agency on OSH through standard setting, research, exchange of information and the provision of technical advisory services. Internationally agreed policies and standards on OSH are embodied in 16 Conventions and two Protocols as well as in 21 Recommendations by the ILO [7]. Since 1948, the Philippines has ratified 31 ILO Conventions, including OSH- related Conventions, such as ILO Conventions (138 and 182) on the Elimination of Child Labor. Initiatives are under way to consider ratification by the Philippine Senate of ILO Convention 155 on Occupational Safety and Health and Working Environment and ILO Convention 161 on Occupational Health Services. Ratification of ILO Convention 155 and the ILO convention on the promotional framework for OSH would give a great boost to OSH practices in the Philippines [17] and a foundation to occupational rehabilitation. In 1991, the Philippines ratified ILO Convention 159 (Occupational Rehabilitation and Employment of Disabled Persons) which ensured occupational rehabilitation be made available to all categories of PWDs and promote their employment in the open labor market [18].

In 2010, the government of the Philippines signed Republic Act 10070 establishing the institutional mechanism to ensure the implementation of programs and services for PWDs in every local government unit (LGU) as envisioned by RA 7277 or the Magna Carta for Disabled Persons. The law promotes the creation of PWD organizations in their respective territorial or regional jurisdiction. A Persons with Disability Affairs Office (PDAO) shall be established in every LGU which covers the province, city, municipality and in the villages (locally called barangays) and is tasked to formulate and implement policies, plans and programs for the promotion of the welfare of PWDs. Representative PWDs in local development councils and other special bodies, ensure that policies, plans and programs for the promotion of the PWDs' welfare are funded by both the national and local government. This new development is valuable for communitybased rehabilitation because $70 \%$ of PWDs are in rural areas [19]. LGUs are the most accessible government machineries on the ground to provide these services to PWDs. This strengthens Executive Order or EO No. 437 
(2005) which encourages the implementation of community-based rehabilitation for PWDs and allocation of funds for such programs by LGUs. EO no. 437 encourages all national government agencies to provide support to the LGUs in carrying out this task [20]. Therefore, from a policy or legislation perspective, the Philippines is provided adequately to start with and carrying out what is in the provision is a challenge.

\section{Government Players in Occupational Rehabilitation}

Occupational rehabilitation in the Philippines is classified into three, namely: institution-based, enterprise-based, and community-based. Institution-based programs are conducted in schools and training centers, enterprise-based in companies, and community based in barangays.

Several other government agencies are mandated to promote occupational rehabilitation. One agency is DOLE which provides employment opportunities to trained and qualified PWDs. The Bureau of Local Development under the DOLE is mandated among others to develop and maintain a responsive occupational guidance and testing system to aid proper human resources allocation. Another agency is the DSWD which manages the social welfare services delivered to PWDs. It operates three disabilityrelated occupational rehabilitation centers, a National Rehabilitation Center and a special office for the Early Child Development Project. The Occupational Rehabilitation Training Centers provide training and employment. According to the Asian Development Bank (ADB), a total of 2,587 PWDs were trained by these facilities as of 2000 .

The DOH operates the Collaborating Center for Disability Prevention, Treatment and Rehabilitation (CCDPTR) which provides accessible rehabilitation and other health services for PWDs. Since only $2 \%$ of PWDs have access to rehabilitation services primarily because the services are mainly available in clinics and hospitals located in urban areas, the CCDPTR improves access to quality health and social services and establishes CommunityBased Rehabilitation Program in all LGUs. The Department also operates the National Orthopedic Hospital and Rehabilitation Medical Center, which is a 700-bed center established in 1945. The National Manpower and Youth Council (now the Technical Education and Skills Development Authority or TESDA) includes occupational rehabilitation training of PWDs as a component of its continuing human resource development program and integrates such occupational rehabilitation in its corporate plan.

DSWD, TESDA and DOLE are three government agencies in the country that have major roles to play in the training of PWDs. TESDA has a network of schools and training located nationwide while DSWD has four strategically located occupational rehabilitation centers in the country. DOLE does not have training centers but it has established partnership arrangements with other government agencies and non-government organizations for the training of PWDs. Courses in the TESDA institutions are open to all types of clients-those with disability or without disability. DSWD occupational rehabilitation centers, on the other hand, were established solely for PWDs. Training programs conducted in all the mentioned government agencies are geared towards gainful employment and self-employment. Enterprise-based programs like apprenticeship and "learnership" are also open to PWDs. However, the oversupply of workers on one hand, and the perceived incapacity of the PWDs on the other hand, limit the PWDs' access to these training programs. Qualified PWDs have the option to take up courses in the formal education system which is composed predominantly of privately owned institutions. The government reserves 5\% of the total allocation of its Private Education Student Financial Assistance Program (PESFA) to PWDs. Aside from this, other scholarship programs are also available for PWDs.

The training program that has provided greater opportunities for the PWDs to acquire skills is the communitybased program. This is because the training is conducted right in the area where the PWDs are situated. The skills being taught here are customized and require only a short duration of training. After finishing the training programs, TESDA encourages the PWDs to undergo assessment and be certified as skilled workers. The DOLE, on the other hand, assists in the PWD graduates in their job search.

Notably, several PWD organizations in the Philippines have started establishing training centers for the members of their sector. While most of the funding requirements (for buildings, equipment, personal services, operating expenses, etc.) come from local and international funding institutions, technical assistance in the areas of trainers training and curriculum development are provided by the government agencies. However, the re-emerging issue of a consolidated national data on the number of PWDs who have participated in occupational rehabilitation is not available. While the NCWDP coordinates the programs or projects for the sector, much still has to be desired in terms of gathering and analysis of data.

In a report for the Expert Group Meeting on Inclusion of PWDS in Occupational Training, it was noted that DSWD, TESDA and DOLE have trained close to 15,000 PWDs in the past 5 years. TESDA has reportedly awarded scholarships for post-secondary technical courses to about 500 PWDs and assessment and certification of the skills were given to around 300 PWDs. These numbers are greatly disproportionate compared to the estimated 8 million PWDs. Further, no monitoring assessment and evaluation 
are made on the outcome of the trainings that were conducted.

\section{Challenges and Recommendations}

Challenges continue to face government initiatives to provide, implement, and monitor a comprehensive occupational rehabilitation program for PWDs. To overcome these challenges, improving data collection, analysis and dissemination should be undertaken aggressively. In the political setup in the Philippines, there is a tendency towards overlapping of functions and monitoring as well as in the generation and dissemination of data which could deter to advance the rehabilitation of PWDs towards gainful employment. Such redundancy could hamper progress in monitoring occupational safety and occupational rehabilitation programs.

While there is some existing mechanisms or platform for occupational safety and health in the Philippines, we did not find any concrete implementation and monitoring mechanisms for occupational rehabilitation. The poor foundation for occupational health as a broad field of practice mirrors the poor occupational rehabilitation programs.

We did not find any evidence of the private sector or the employers pushing for robust and relevant occupational rehabilitation programs. From a workers' health perspective, this seems to be not logical given the fact that the private sector is a large employer in the Philippines. This problem might have stemmed from the lack of implementation and monitoring infrastructure from the government side.

Advocacy, networking and resource mobilization may help in establishing linkages between occupational rehabilitation, productivity and economic growth through research and practice. In the Philippines context, occupational rehabilitation included specialized occupational guidance provided by DSWD, occupational training and placement by TESDA, and employment by DOLE. Monitoring and evaluation of programs should be harmonized in order to improve these agencies and other national, regional and local agencies of the government.

Another challenge is the lack of formal training of professionals who deal with the employment of PWDs. Hence, special education or certification in occupational rehabilitation is recommended for medical and rehabilitation professionals. Such an undertaking may be pursued in addition to the development of national occupational titles and work profile in the Philippines and an effective system for the assessment of work loss and diminished earning capacity. Moreover, the government along with the academic community (e.g. universities) may establish a centre of excellence for clinical development and evidence-based practices in the field of occupational rehabilitation.

There is also a need to harmonize application and diagnostic reporting. While the International Classification of Diseases (ICD) is now being applied to claims submitted by SSS for benefits arising from disabilities and workrelated illnesses, this is not the case with regard to GSIS claims. Those who work for the government agencies, government financial institutions (GFIs), most of the government owned and controlled corporations (GOCCs) are GSIS members. Excluded are members of the Armed Forces of the Philippines. Those who worked for private corporations are SSS members.

In summary, the policy, system and service on occupational rehabilitation may be evident in the Philippines at first glance, but are underdeveloped particularly around initiation of effective programs and their implementation. Infrastructures aimed at improving work participation among individuals with associated health conditions, are insufficient in addressing work disability. However, based on this paper, this insufficiency may be more pronounced on issues affecting injured workers than PWDs in general. The benefits system (e.g. in occupational rehabilitation) in the Philippines does not make a clear distinction between PWDs in general and injured workers and is seemingly geared towards mortality and sick leave rather than the physical, psychological, and social functioning of the individual in daily life and work. Occupational rehabilitation is included as a component of work disability management but we did not find reference to early and sustainable return-to-work for injured workers in particular. Moreover, examining the effectiveness of occupational rehabilitation in the Philippines have not been established and could be explored further in the future.

The majority of people engage in some form of work or occupation in their lives. Health conditions or health-related events may happen that would limit or restrict a person's ability to work and this makes occupational rehabilitation important in order to facilitate early, successful, and sustained return-to-work. Occupational rehabilitation plays an essential role in the area of addressing work disability and at the same time encouraging participation of individuals in the society and workforce. As a program, occupational rehabilitation is fundamental in mitigating work disability and could contribute to improve overall quality of life. Therefore, a systematic understanding, generation and mandatory reporting of occupational data and events would advance the occupational rehabilitation agenda in the Philippines. Such efforts would also improve the care of those individuals so gainful employment could be achieved. 


\section{References}

1. Escorpizo R, Ekholm J, Gmunder HP, Cieza A, Kostanjsek N, Stucki G. Developing a core set to describe functioning in vocational rehabilitation using the International Classification of Functioning, Disability, and Health (ICF). J Occup Rehabil. 2010;20(4):502-11.

2. Johnstone B, Reid-Arndt S, Franklin KL, Harper J. Vocational outcomes of state vocational rehabilitation clients with traumatic brain injury: a review of the Missouri Model Brain Injury System Studies. NeuroRehabilitation. 2006;21:335-47.

3. Rogers ES, Anthony WA, Lyass A, Penk WE. A randomized clinical trial of vocational rehabilitation for people with psychiatric disabilities. Rehabil Couns Bull. 2006;49:143.

4. Selander J. Unemployed sick-leavers and vocational rehabilitation-a person level study based on a national social insurance material. Ph. D. thesis. Karolinska Institute, Department of Rehabilitation Medicine, Stockholm, Sweden; 1999.

5. Making the MDGs inclusive: Empowerment of Persons with Disabilities and their communities around the world, 2009.

6. Government of the Philippines. Rules and Regulations Implementing the Executive Order 261: Creating an Inter-agency Committee on Employment Promotion, Protection and Rehabilitation of Persons with Disabilities, 1995.

7. United Nations Economic and Social Commission for Asia and the Pacific. Disability at a Glance: A Profile of 28 Countries and Areas in Asia and the Pacific, 2006.

8. Department of Labor and Employment, Employees' Compensation Commission (Philippines). Employees' compensation and state insurance fund (with implementing rules), Presidential Decree No. 626 (as amended), 2010 edition. Makati, Philippines. Available from: http://www.ecc.gov.ph/pd626.htm.

9. National Statistic Office (Philippines). Results from the January 2010 Labor Force Survey (LFS). Available from: http://www. census.gov.ph/data/pressrelease/2010/lf1001tx.html.

10. Bureau of Labor and Employment Statistics, Department of Labor and Employment (Philippines). Safety and Health Practices in the
Wholesale and Retail Trade; Repair of Motor Vehicles, Motorcycles, Personal and Household Goods Industry: 2008 (Ninth of a series on Industrial Relations Practices). Labstat Updates 2010; 14(32).

11. Bureau of Labor and Employment Statistics, Department of Labor and Employment (Philippines). Safety and Health Practices in Other Community, Social and Personal Service Activities: 2008 (Tenth of a series on Industrial Relations Practices). 2010;14(34).

12. Bureau of Labor and Employment Statistics, Department of Labor and Employment (Philippines). Frequency Rates of Cases of Occupational Injuries With Workdays Lost in Non-Agricultural Establishments Employing 20 or More Workers by Industry and Incapacity for Work, Philippines, 2007.

13. Bureau of Labor and Employment Statistics, Department of Labor and Employment (Philippines). Cases of Occupational Injuries With Workdays Lost In Non- Agricultural Establishments Employing 20 or More Workers by Industry and Type of Injury. 2007.

14. Estrella-Gust DP. Occupational Safety and Health Center (Philippines), 2006.

15. World Health Organization. International classification of functioning, disability and health. Geneva: WHO; 2001.

16. Sandqvist JL, Henriksson CM. Work functioning: a conceptual framework. Work. 2004;23(2):147-57.

17. Government of the Philippines. National Occupational and Safety Health (OSH) Profile, 2006.

18. International Labour Organization. Convention concerning vocational rehabilitation and employment (disabled persons). Geneva: International Labour Organization, 1983;C159(69).

19. Periquit A. Community Based Rehabilitation in the Philippines, International Disability Studies, 1989.

20. Expert Group Meeting on Inclusion of PWDS in Occupational Training: Country Report for the Philippines. Bangkok, Thailand; 14-16 February 2006. 